\title{
Individual level dynamics of PTV change across the electoral cycle
}

Abstract. Propensity-to-vote (PTV) scores are ever more commonly used in electoral research as a measure of electoral utilities. Yet a growing literature employs them as dependent variable in the voting equation in place of the lower information granted by vote recall questions. However, this choice can be seen as problematic because of the very structure of election survey research. To the extent that voters' PTVs are measured in post-election surveys (as it is often the case) these are likely to result endogenously produced by actual voting behavior in the past election - thus partly undermining the validity of the PTV question which, ideally, should not be related to any specific election. In this paper, we try to disentangle the relationship between short-term political attitudes (leader evaluations, issue proximity, economic assessments) and voters' changing patterns of propensities to vote in both an electoral and a non-electoral context. The latter scenario serves as a means to rule out the potentially contaminating effect of voting choices on voters' PTVs. The data comes from two panel surveys of Italian voters conducted by ITANES in occasion of the 2006 general election, and in 2011 (that is, in a non-electoral year) respectively.

Keywords: applied methodology, electoral utilities, Italian politics, leader effects, political attitudes, voting behavior 


\section{Introduction}

The last two decades have witnessed the burgeoning of empirical voting research making use of PTV measures (Tilllie, 1995; van der Eijk and Franklin, 1996; van der Eijk et al, 2006; van der Brug and Mughan, 2007; van der Brug et al., 2007; van der Brug et al., 2008; van der Eijk and Franklin, 2009). An interval-level measure of electoral utility overcomes many drawbacks related to the nominal nature of the dependent variable of electoral research in multi-party systems, and allows researchers to model voting choices with a higher degree of methodological accuracy (van der Eijk, 2002).

According to van der Eijk et al (2006) PTV scores are to be understood as a cardinal measure of the perceived utility proceeding from political parties to individual voters. As opposed to probability measures, PTVs are not bounded to sum to any fixed amount (i.e., in the case of probabilities to one). This non-ipsative feature of voting propensities is tightly related to the cardinal character of this measure. This fundamental feature of PTV scores is obtained by introducing a projective element postponing voters' choice in an undefined future within the question wording:

"Would you indicate for each party how probable it is that you will ever vote for that party?" (van der Eijk and Niemoller, 1983)

From a theoretical point of view, PTVs' coordinates are to be found in random utility theory, which interprets the electoral utilities perceived by voters as a random variable and the subsequent voting choice as a deterministic process (Manski and Lerman, 1977). On these bases, PTVs lie at the core of a two-stage model of voting. In the first stage, voters assess the electoral utilities coming from each party in the choice set. In the second one, voters use this estimated electoral utility to formulate their voting decision (van der Brug et al, 2007; Ch. 2) . 
The use of PTVs as dependent variable of voting research has two important advantages. From a methodological point of view, it permits to avoid the drawbacks inherent to the use of discrete choice models (for a better discussion of this point, see: van der Brug and Mughan, 2007). Secondly, moving from a nominal to a cardinal dependent variable also enables quantitative researchers to overcome problems intrinsic to cross-country comparative analyses (van der Eijk and Franklin, 1996; van der Brug et al., 2008). This last feature is related to the fact that PTVs switch simultaneously the level of analysis as well as the level of conceptualization. Indeed, the level of analysis shifts downwards from the individual to the intra-individual level, forcing one to reinterpret both the dependent and the independent variables in terms of individual*parties relationships. From a conceptual point of view, the object of analysis is no longer a specific party, but a generic one (regardless of the specific characteristics of the party system).

Notwithstanding, the propensity to vote for a party and the actual choice to vote for that party remain two separate phenomena. A high propensity score for a specific party does not necessarily imply that the voter will choose that party at the ballot: other parties may have equally high, or even higher scores. Strategic considerations may also be at work (Rosema, 2006). The attractiveness of emerging political leaders can represent as well a source of crosspressure for voters - this being ever more the case in times of personalization of politics (McAllister, 2007; Garzia, 2011). For sure PTVs and the vote are closely connected, but the individual-level dynamics underlying this connection remain unclear. Suffice it to say that, in terms of electoral survey research, the very same question wording may capture different meanings if asked before or after the election. Pre-electoral PTVs can easily be thought as having a causal impact on voting intentions. In the case of post-electoral surveys, propensities to ever vote for a party are likely to be "colored" to at least some extent by respondents' voting choice in the last election. 
To the best of our knowledge, no empirical study has ever investigated the drivers of change in patterns of PTVs as well as the role of actual voting behavior in the process of change. In order to provide initial answers to these questions and fill this relevant gap in the PTV literature, we make use of national election study data from the Italian case. The two studies that will be employed, from 2006 and 2011 respectively, provide us with the unprecedented chance to look at the meaning of PTVs before and after elections, as well as in a non-electoral year. The employment of panel data will also allow to appraise the actual stability of PTVs throughout time as well as the main drivers of change.

\section{Data and Methods}

The data employed in this analysis comes from two mass surveys conducted by the ITANES ${ }^{1}$ team in $2006(n=1377)$ and $2011(n=2362)$ respectively. The former was conducted in occasion of the 2006 general elections. Respondents were interviewed twice, i.e., before (February/March) and after the election took place (April/June). As to the 2011 study, this is peculiar for it features two panel waves from a non-electoral year (first wave fieldwork: February/May; second wave: October/November). A comparison of 2006 and 2011 is profitable to our purposes for it enables to rule out the potentially confounding effect of voting behavior on respondents' pattern of propensity to vote. Each wave from both surveys features all the relevant measures of interest for this analysis, as outlined below. Furthermore, it must be noted that question wording has been kept fully comparable throughout surveys.

\footnotetext{
1 The ITANES (Italian National Election Studies) Association runs a research program on voting behavior in Italy, the origins of which date back to the early 1990s, when the Istituto Carlo Cattaneo Research Foundation conducted two post-election surveys (1990 and 1992) within the context of a project devoted to the study of change in the Italian political system. For the 1994 elections the Cattaneo's research program was joined by various researchers from several different universities, and in December 2007 they founded the ITANES Association. Further information is available at http://www.itanes.org. The analyses, interpretations, and conclusions in this paper are solely those of the authors.
} 
In line with the existing literature on PTVs, we stack our data in order to obtain a structure defined at the level stemming from the interaction of individuals and parties (van der Eijk et al., 2006). Following the logic of the stacked data matrix, the unit of analysis is represented by respondent*party combinations. The dependent variable is a 10 -point scale probing voters' propensity to ever vote for each of the parties included as stacks. ${ }^{2}$

All the main attitudinal predictors are already interpretable in terms of respondent*party combination. Party identification is measured through the usual combination of survey questions tapping both the directional and the strength component: respondents are thus assigned a value ranging from 0 (not identified with the party in the specific combination) to 3 (strongly identified with that party). Respondents' evaluation of party leaders is tapped by the thermometer score probing their personality assessment on a 10-point scale, whereas ideological proximity is measured as the absolute difference between the respondents' placement of the self and each of the parties on the left-right scale.

The statistical model also controls for the effect exerted by socio-demographic characteristics of respondents (age, gender, educational level), their placement within the socioeconomic structure (urbanization, region of residence, religious denomination, profession), and their retrospective evaluation of the economy in the last year. Contrary to the aforementioned attitudinal variables, our statistical controls do not have a straightforward counterpart at our level of analysis (respondents*parties). For this reason, we have produced the so-called $y$-hats that is, predicted values - regressing our dependent variable on synthetic indexes of the variables of interest though OLS, in order to produce a linear projection (at the respondent*party level) of previously individual variables. The analysis also controls for the

\footnotetext{
2 Parties included as stacks with respect to each dataset are as follows: (2006) Alleanza Nazionale, Democratici di Sinistra, Forza Italia, Lega Nord, La Margherita, Rifondazione Comunista, Unione dei Democratici Cristiani e di Centro, Verdi; (2011) Futuro e Libertà per l'Italia, Partito Democratico, Popolo della Libertà, Lega Nord, Italia dei Valori, Sinistra Ecologia e Libertà, Unione dei Democratici Cristiani e di Centro.
} 
effect of party size (measured at the percentage vote shares obtained by each party in the previous relevant election) that, especially in multi-party systems, is known to increase voters' propensity to vote for larger parties (van der Eijk and Franklin, 1996; 2009).

\section{Results}

As a preliminary step, we estimated four OLS models with the aim of uncovering the underlying structure of vote propensities for the main Italian parties. In Table 1 we present ordinary least squares estimates of propensities to vote in 2006, taking into account data from both the preand the post-electoral wave separately, and in 2011 (a non-electoral year) focusing crosssectionally on each wave in turn. Our simple model relies on the standard explanatory variables (as presented above) that have been identified by electoral researchers as the most relevant predictors of voting choice in Western democracies (Thomassen, 2005), as well as in the Italian case (Bellucci and Segatti, 2011). In this exploratory section of the analysis we simply observe the effect exerted by these variables on electoral utilities in the surveys at hand.

The picture emerging from the standardized estimates reported in Table 1 fits well with the most recent voting literature from the Second Italian Republic, which stresses the strong personalization of the political system and of voting choices in turn (Garzia and Viotti, 2011). In fact, leader evaluations emerge as the strongest predictor of PTVs in each and every model. In terms of explanatory power, party leader assessments are followed by party-voter proximity on the left-right scale. Socio-structural and economic controls, on the contrary, do not seem to play much of a role - in line, once again, with the available empirical evidence that demonstrates the declining ability of socio-structural factors to influence Italian voters' behavior.

More interestingly to our purposes is the observation of an extremely stable pattern of coefficients throughout the surveys. Regardless of the political context in which the various surveys have been conducted (i.e., electoral vs. non-electoral periods) the structural content of 
Italian voters' PTVs appears by and large shaped by inherently political factors, and in primis by thermometer assessments of the political leaders. Indeed, it should be noted that the role played by leader evaluations becomes even more important in 2011 (columns 3 and 4). During the campaign electoral utilities appear relatively more influenced by ideological considerations, while their salience in a non-electoral context gets downsized by about 50 percent. In the latter circumstance, voters would seem to rely less on ideology in the formulation of their electoral utilities, while even greater role is left to the perception of party leaders. ${ }^{3}$

$<$ Table 1 about here $>$

Overall, the relative importance of our statistical predictors in shaping electoral utilities would seem rather stable over the whole time span covered by the data. But what can be said about the individual-level stability of PTVs throughout time? At first, we have correlated our PTV measures taken from the first wave of each survey with their counterpart in the second wave. The reported Pearson's correlation between the two time points is .66 and .67 in 2006 and 2011 respectively. Interestingly, these values show a virtually identical degree of association across waves in both the electoral and the non-electoral contexts. Perceived electoral utilities appear rather stable, but they are not fixed - even in the relatively short time elapsed between the first and the second wave of the surveys (i.e., about six months). The question is then: what drives a change in the perceived electoral utilities?

\footnotetext{
3 These results are possibly biased by unobservable omitted variables that, if correlated with PTV values as well as with some explanatory variable in our model, might lead to inconsistency of the estimates. Therefore, we further controlled for the presence of individual fixed unobserved heterogeneity at the individual level by re-estimating the models with a fixed-effect design. Fixed-effects estimates further admit the possibility that the source of unobservable heterogeneity is correlated with one or more of the observable regressors. Failure to consider this source of endogeneity (if present) would lead to inconsistent estimates. Hence, we produced OLS estimates on the model transformed deviations from the individual time means (fixed-effects estimates). Results are so similar to previous simple OLS estimates that we decided, for the sake of simplicity, to simply report the latter ones.
} 
This question can only be addressed through a proper specification of the empirical model. To this purpose, we have computed a variable that captures the difference between the first- and the second-wave values of the PTVs. For 2006, we obtain a variable that approximates a normal distribution centered around a mean value of .49 with a standard deviation of 2.56 (the range is between -10 and +10 ; see Figure 1, Panel A). Parties' campaign activities clearly exert an effect on voters' propensity to vote for them. Indeed, it is worth noting that the average increase in PTVs holds for each and every party under analysis, regardless of their size, incumbency status and final electoral result. ${ }^{4}$ As for 2011, the variable produces a mean change of 0 and a standard deviation of 2.63 (see Figure 1, Panel B). Evidently, the absence of a real election slows down substantially the patterns of change.

$<$ Figure 1 about here>

We restructured our stacked data matrix using as new dependent variable the difference in PTVs (i.e., $\mathrm{PTV}_{\mathrm{t} 2}-\mathrm{PTV}_{\mathrm{t} 1}$ ). We have re-estimated the $y$-hat values for the socio-structural variables, which are obviously not expected to change in the short term. As to the attitudinal measures included in the model, we computed the first differences for the measures of partisanship, party-voter proximity on the left-right scale, leader assessments as well as retrospective economic evaluations. Our empirical model of PTV change can be stated as follows:

$$
\text { D.Ptv }=a+b_{1} \text { D.Pid }+b_{2} \text { D.Lead }+b_{3} \text { D.Issues }+b_{4} \text { D.Econ }+\boldsymbol{b X}+u_{i}
$$

\footnotetext{
${ }^{4}$ The average increase in PTVs across the electoral period is as follows: Alleanza Nazionale (.39), Democratici di Sinistra (.50), Forza Italia (.34), Lega Nord (.26), La Margherita (.47), Rifondazione Comunista (.57), Unione dei Democratici Cristiani e di Centro (.91), Verdi (.39)
} 
So, what drives changes in PTVs? Our first-differences models (as presented in Table 2, columns 1 and 4) show that changes in the score attributed to party leaders play the greatest role in PTV dynamics. Changes on the relative party-voter distance on issues as well as on the partisanship dimensions play only a secondary role. It would thus appear that patterns of PTV change are most strongly affected by changes in those factors that shape them more heavily: party leader assessment. ${ }^{5}$

$<$ Table 2 about here>

We also tried to introduce voting choice itself as a predictor of PTV change in the 2006 model (Table 2, column 2). While recognizing that in the prevailing view voting choice should be deterministically produced as a result of the individual's calculus of voting propensities (and hence a model of PTV that includes vote as predictor should be seen as mispecified), we are interested in understanding whether PTVs are vulnerable to a feedback effect proceeding from voting choice. In this alternative framework, PTVs might incorporate an individual bias related to the rationalization of the act of voting, which may raise the evaluation of the party towards which the ballot has been cast. Evidence shows that voting choice has a significant but only modest role in PTV changes $(\beta=.03)$, making the feedback hypothesis very difficult to hold.

As a further check, we included a statistical control tapping the increase/decrease of party's vote shares in the 2006 election as compared to the previous general election (Table 2, column 3). The effect of aggregate electoral gains on PTVs is statistically significant and signed as expected - parties winning more votes than in the previous election do become more

\footnotetext{
5 To check for the robustness of this finding, we also tested the alternative hypothesis by which changes in party leader evaluations are casued by (rather than causes of) changing patterns of propensity to vote. This hypothesis is nonetheless falsified by the results of a number of Granger's tests, which show that the effect of leader evaluations (pre) on PTVs (post) is in every case stronger than that exerted by PTVs (pre) on leader evaluations (post).
} 
attractive to voters. Yet the inclusion of this variable do not add substantially to the explanatory power of the model, nor it alters in any way the coefficients of the other variables.

\section{Concluding Remarks}

PTV measures are ever more commonly used as the dependent variable of electoral research. However, this choice can possibly represent a problem because of the very structure of election survey research. To the extent that voters' PTVs are measured in post-election surveys (as it is often the case), these are in danger of resulting endogenously produced by actual voting behavior in the past election. Our preliminary results, based on Italian election study data, show that this is not the case. Italian voters' pattern of propensity(es) to vote are by and large not vulnerable to a feedback effect proceeding from voting choice. The drivers of PTVs are indeed inherently political factors, such as voters' assessment of party leaders and their proximity to parties on the left-right scale. According to our findings, these factors are also the principal drivers of PTV-change throughout time.

In turn, these results provide support for the notion of PTVs as a concept projected in an undefined future (van der Eijk et al, 2006). Italian voters would seem to understand the difference between actual vote choices and the likelihood to ever vote for a party (with the former bearing only a modest effect on the latter). Needless to say, more research on individual country cases as well as in comparative perspective is in order if we are to understand the extent to which these conclusions hold beyond the borders of Italian (often claimed) uniqueness. 


\section{References list}

Bellucci, P., and Segatti, P. (2011). Votare in Italia, Dall'appartenenza alla scelta. Bologna: Il Mulino.

van der Brug, W., Franklin, M., and Tóka, G. (2008). One electorate or many? Differences in party preference formation between new and established European democracies. Electoral Studies 27: 589-600.

van Der Brug, W., and Mughan, A. (2007). Charisma, leader effects and support for rightwing populist parties. Party Politics 13: 29-51.

van der Brug, W., van der Eijk, C., and Franklin, M. (2007). The economy and the vote: Economic conditions and elections in fifteen countries. Cambridge University Press, .

van der Eijk, C. (2002). Design issues in electoral research: taking care of (core) business. Electoral Studies 21: 189-206.

van der Eijk C., and Niemoller B. (1983). Electoral change in the Netherlands: empirical results and methods of measurement. Amsterdam: CT Press.

van der Eijk, C., and Franklin, M. (1996). Choosing Europe?: the European Electorate and National Politics in the face of Union. Ann Arbor: University of Michigan Press.

van der Eijk, C., and Franklin, M. (2009). Elections and voters. Basingstoke: Palgrave Macmillan.

van der Eijk, C., van der Brug ,W., Kroh, M., and Franklin, M. (2006). Rethinking the dependent variable in voting behavior: On the measurement and analysis of electoral utilities. Electoral Studies 25: 424-47.

Garzia, D. (2011). The Personalization of Politics in Western Democracies Causes and Consequences on Leader-Follower Relationships. The Leadership Quarterly 22: 697709.

Garzia, D., and Viotti, F. (2011). Leader, identitá di partito e voto in Italia, 1990-2008. Rivista Italiana di Scienza Politica 41: 411-32.

Manski, C., and Lerman, S. (1977). The estimation of choice probabilities from choice based samples. Econometrica 45: 1977-88.

McAllister, I. (2007). The Personalization of Politics. In: R. Dalton and H. Klingemann (eds.), The Oxford handbook of political behavior. Oxford: Oxford University Press. 
Rosema, M. (2006). Partisanship, candidate evaluations, and prospective voting. Electoral Studies 25: 467-88.

Thomassen, J. (ed.) (2005). The European voter: a comparative study of modern democracies. Oxford: Oxford University Press.

Tillie, J. (1995). Party utility and voting behavior. Amsterdam: Het Spinhuis. 
Table 1. The determinants of PTVs: ordinary least squares estimation

\begin{tabular}{|c|c|c|c|c|}
\hline & \multicolumn{2}{|c|}{2006} & \multicolumn{2}{|c|}{2011} \\
\hline & (1) & (2) & (3) & (4) \\
\hline Age & $.00(.18)$ & $.01(1.93)$ & $.01(1.44)$ & $.00(.88)$ \\
\hline Gender & $.01(.96)$ & $.04(4.19)$ & $-.01(-1.63)$ & $-.01(-1.88)$ \\
\hline Educational level & $-.01(-1.51)$ & $.02(3.32)$ & $.00(.58)$ & $.01(2.31)$ \\
\hline Urbanization & $-.02(-2.61)$ & $.02(2.00)$ & $-.02(-2.93)$ & $.01(.89)$ \\
\hline Region of residence & $-.03(-3.44)$ & $.03(3.80)$ & $-.04(-5.32)$ & $.01(1.11)$ \\
\hline Religious denomination & $-.01(-1.31)$ & $.03(3.98)$ & $-.01(-1.45)$ & $.02(5.07)$ \\
\hline Profession & $-.04(-4.46)$ & $.04(5.14)$ & $-.03(-4.10)$ & $.04(4.20)$ \\
\hline Party Identification & $.19(22.96)$ & $.17(27.36)$ & $.19(35.40)$ & $.20(35.86)$ \\
\hline Leader Evaluation & $.45(34.84)$ & $.45(38.62)$ & $.52(51.51)$ & $.52(48.77)$ \\
\hline Ideological Proximity & $-.26(-22.47)$ & $-.31(-29.61)$ & $-.16(-15.49)$ & $-.16(-16.18)$ \\
\hline Economic Assessment & $-.01(-0.84)$ & $.04(5.46)$ & $-.03(-4.20)$ & $.01(1.57)$ \\
\hline Party Size & $.08(11.60)$ & $.06(11.03)$ & $.05(9.40)$ & $.05(10.77)$ \\
\hline Adjusted $\mathrm{R}^{2}$ & .54 & .63 & .51 & .50 \\
\hline$F$ & $\begin{array}{c}F(12,1083) \\
=903\end{array}$ & $\begin{array}{c}F(12,1180) \\
\quad=1395\end{array}$ & $\begin{array}{l}F(12,1882) \\
\quad=1222\end{array}$ & $\begin{array}{c}F(12,1912) \\
=992\end{array}$ \\
\hline $\mathrm{N}$ & 8048 & 9030 & 12287 & 12662 \\
\hline
\end{tabular}

Note: Dependent variable: PTV on a stacked data matrix. Table entries are standardized OLS regression coefficients. Table entries are fully standardized OLS regression coefficients. T-statistics (in parentheses) are based on clustered robust standard errors at the individual level. 
Figure 1, Panel A. Distribution of PTV differences across panel waves, 2006

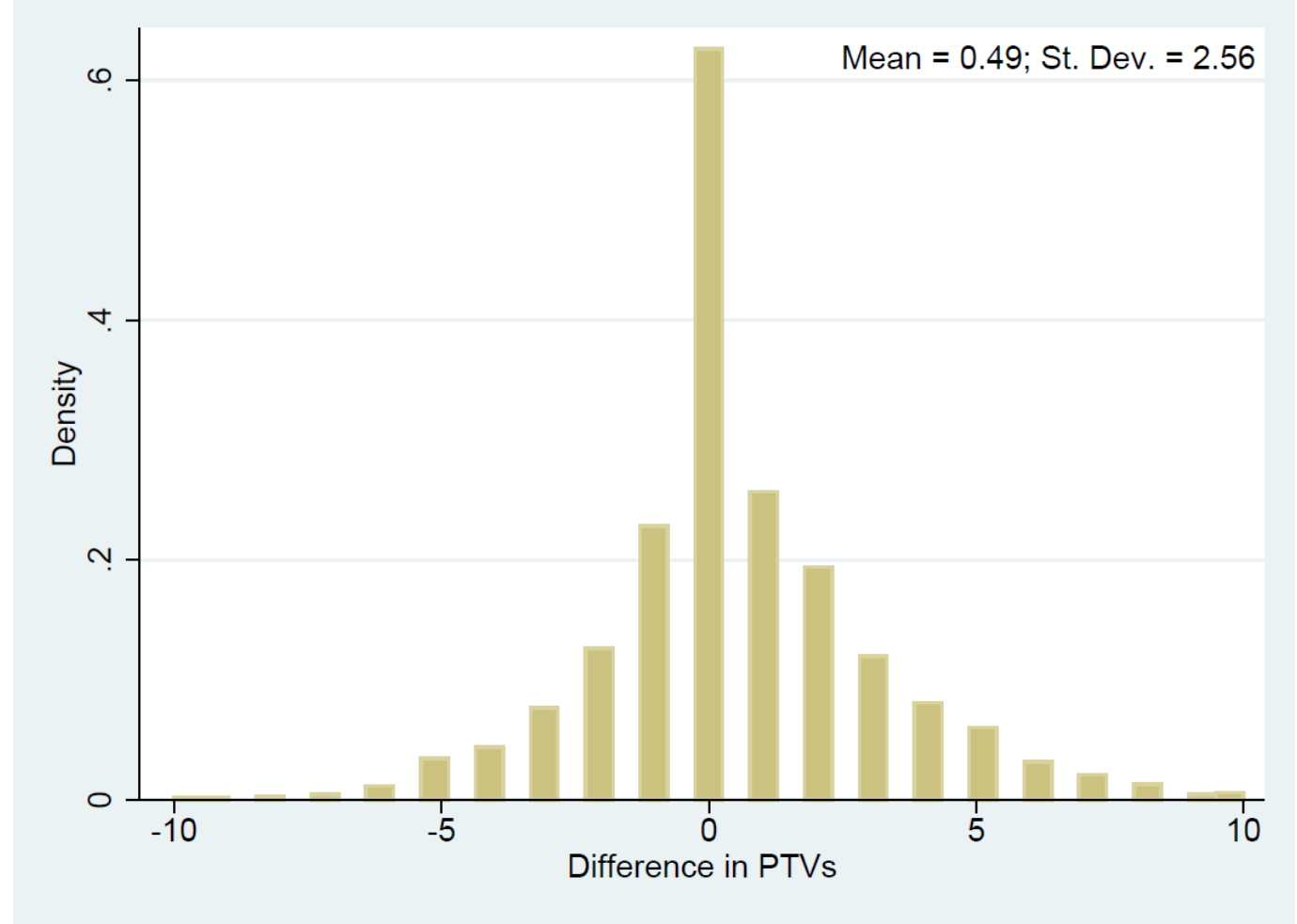

Figure 1, Panel B. Distribution of PTV differences across panel waves, 2011

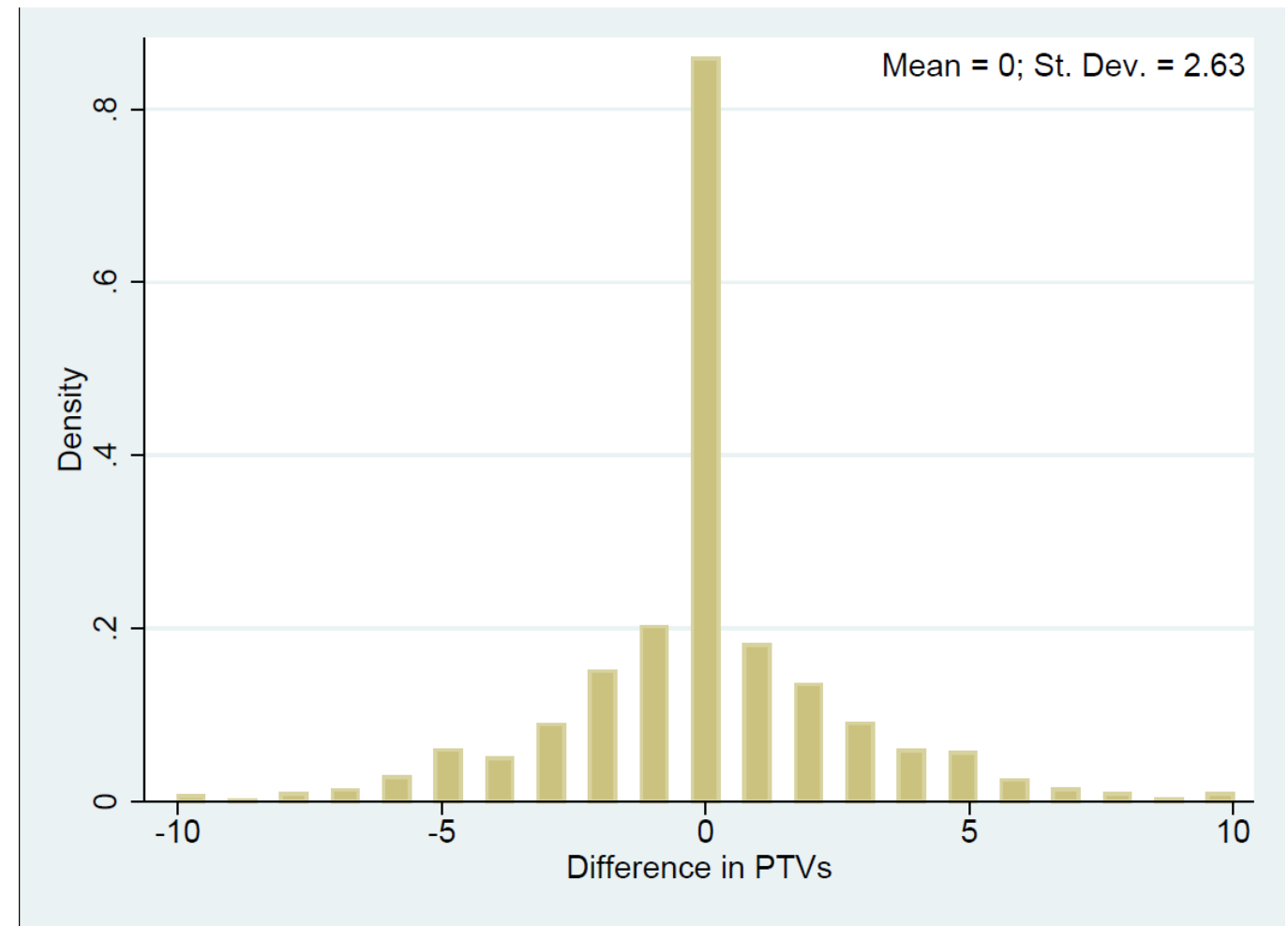


Table 2. The drivers of PTV change: first-differences models

\begin{tabular}{|c|c|c|c|c|}
\hline & \multicolumn{3}{|c|}{2006} & \multirow{2}{*}{$\frac{2011}{(4)}$} \\
\hline & (1) & (2) & (3) & \\
\hline Age & $.01(.68)$ & $.01(.78)$ & $.01(.81)$ & $-.01(-.82)$ \\
\hline Gender & $.03(2.58)$ & $.03(2.60)$ & $.04(2.72)$ & $.02(1.57)$ \\
\hline Educational level & $.04(3.36)$ & $.04(3.35)$ & $.04(3.39)$ & $.01(1.32)$ \\
\hline Urbanization & $.06(4.95)$ & $.06(4.97)$ & $.06(4.97)$ & $.04(4.01)$ \\
\hline Region of residence & $.10(7.25)$ & $.10(7.23)$ & $.10(7.24)$ & $.08(7.82)$ \\
\hline Religious denomination & $.07(5.42)$ & $.07(5.42)$ & $.07(5.41)$ & $.04(4.12)$ \\
\hline Profession & $.11(9.25)$ & $.11(9.30)$ & $.11(9.34)$ & $.10(7.05)$ \\
\hline Party Identification $(\Delta)$ & $.08(7.93)$ & $.07(6.77)$ & $.07(6.70)$ & $.06(8.39)$ \\
\hline Leader Evaluation $(\Delta)$ & $.23(16.08)$ & $.23(16.13)$ & $.23(16.04)$ & $.19(15.25)$ \\
\hline Issue Proximity $(\Delta)$ & $-.10(-6.89)$ & $-.10(-6.95)$ & $-.10(-6.94)$ & $-.07(-5.47)$ \\
\hline Economic Eval. $(\Delta)$ & $.01(1.18)$ & $.01(1.26)$ & $.01(1.27)$ & $.03(2.79)$ \\
\hline Vote Choice & - & $.03(3.32)$ & $.04(3.62)$ & - \\
\hline $\operatorname{Party} \operatorname{Size}(\Delta)$ & - & - & $.04(4.17)$ & - \\
\hline Adjusted $\mathrm{R}^{2}$ & .13 & .13 & .13 & .08 \\
\hline & $\mathrm{F}(11,1016)$ & $F(12,1016)$ & $F(13,1016)$ & $\mathrm{F}(11,1689)$ \\
\hline$F$ & $=57$ & $=53$ & $=52$ & $=51$ \\
\hline $\mathrm{N}$ & 7516 & 7516 & 7516 & 10811 \\
\hline
\end{tabular}

Note: Dependent variable: D.ptv $\left(\mathrm{PTV}_{\mathrm{t} 2}-\mathrm{PTV}_{\mathrm{t} 1}\right)$ on a stacked data matrix. Table entries are fully standardized OLS regression coefficients. T-statistics (in parentheses) are based on clustered robust standard errors at the individual level. 